\title{
Central venous catheter use in UKCCSG oncology centres
}

D A Tweddle, K P Windebank, A M Barrett, D C Leese, R Gowing, on behalf of the United Kingdom Children's Cancer Study Group* and the Paediatric Oncology Nursing Forum $\dagger$

\begin{abstract}
A cross sectional audit of central venous catheter (CVC) use was performed in United Kingdom Children's Cancer Study Group oncology centres. There were wide variations in choice of line, insertion technique, aftercare practice, and diagnosis of CVC related sepsis. These variations highlight the difficulty in interpretation of published data on CVC efficacy.

(Arch Dis Child 1997;77:58-59)
\end{abstract}

Keywords: paediatric oncology; central venous catheter

The use of central venous catheters (CVCs) is associated with significant morbidity and sometimes mortality. ${ }^{1-6}$ This makes it imperative to identify factors that may predispose to complications. The aims of this study were: (1) to characterise CVC use, insertion techniques, and reinsertion rates, (2) to identify variations in aftercare practice, and (3) to survey opinion of diagnosis of CVC related sepsis among multiple centres belonging to a single cooperative cancer study group.

The study involved collaboration of physicians and surgeons of the United Kingdom Children's Cancer Study Group (UKCCSG) and nurses from the Paediatric Oncology Nursing Forum.

\section{Methods}

Any child with cancer requiring CVC insertion, treated at a UKCCSG centre, was eligible for the study. Over a six month period, data forms relating to patient and line insertion details, aftercare policy, and diagnosis of CVC related sepsis were collected. Children's Cancer Study Group D A Tweddle K P Windebank A M Barrett R Gowing

Paediatric Oncology Nursing Forum D C Leese

Correspondence to: Dr K Windebank,

Department of Child Health, Royal Victoria Infirmary, Queen Victoria Road, Newcastle upon Tyne NE1 4LP.

Accepted 12 March 1997
United Kingdom eters were inserted in $84 \%$ of cases and subcutaneous ports in $16 \%$. Of the external catheters, $36 \%, 62 \%$, and $2 \%$ were single, double, and triple lumen, respectively. Whereas $60 \%$ of centres did not use subcutaneous ports, in three centres $40 \%$ of CVCs were of this type. Only one centre used triple lumen external catheters. The ratio of external catheters to subcutaneous ports was approximately 5:1 for all diagnoses except acute myeloid leukaemia and bone tumours, where the proportion of external catheters was even higher, and in brain tumours, where the proportion of subcutaneous ports was increased. In $74 \%$ of cases this was a first insertion; in $21 \%, 4 \%$, and $1 \%$ it was the second, third, and fourth respectively. Thus $26 \%$ of CVCs were reinsertions. This was not found to be associated with age or diagnosis.

There was wide variation in surgical insertion technique (table 1). Most surgeons used the right internal jugular vein, which they repaired. Most lines were fixed with at least a cuff suture and the tip positioned in the right atrium. Concurrent operative procedures, for example lumbar puncture, were performed in $20 \%$ of cases and prophylactic antibiotics given in $22 \%$

There was considerable variation among the 21 centres with respect to aftercare techniques. Subcutaneous ports were flushed monthly in $88 \%$ of centres, Broviac external catheters twice weekly in $60 \%$ (range daily to weekly), and Hickman external catheters weekly in $45 \%$ (range daily to every two weeks). External catheters were flushed with $5 \mathrm{ml}$ of $10 \mathrm{U} / \mathrm{ml}$ heparinised saline in $76 \%$ of centres (range 2.5

Table 1 Aspects of surgical technique

\begin{tabular}{ll}
\hline Procedure & $\begin{array}{l}\text { \% CVCs inserted by this } \\
\text { technique }(n)\end{array}$ \\
\hline Bevel cut on line & $43(326)$ \\
Entry vein & $(247)$ \\
Right internal jugular & 54 \\
Left internal jugular & 19 \\
Other & 27 \\
Entry vein & $(312)$ \\
Repaired & 72 \\
Ligated & 28 \\
Fixation & $(330)$ \\
Cuff suture & 76 \\
Exit site suture & 44 \\
Both & 32 \\
Tip position & $(224)$ \\
SVC & 21 \\
RA/SVC junction & 11 \\
RA & 62 \\
IVC & 2 \\
Other & 4 \\
\hline
\end{tabular}

RA/SVC junction $=$ right atrium/superior vena cava junction; $\mathrm{RA}=$ right atrium; $\mathrm{IVC}=$ inferior vena cava $\mathrm{SVC}=$ superior vena cava.
^ UKCCSG membership of joint supportive care group: D Tweddle, D Walker, J Walker, R Wheeler, K Windebank. † PONF membership of joint supportive care group: J Auty, S Cook, O Cresswell, D Hodson, D Leese, H Lucas, C Philpott, A Thompson, E Yeomans.

Results

Of 22 UKCCSG centres, 13 participated, returning 347 insertion data forms. Participadistribution and diagindividual cancers in the UK population and whether intensive chemotherapy requiring 
Table 2 Results of questionnaire for criteria for diagnosing CVC colonisation (10, strongly agree; 0 , strongly disagree)

\begin{tabular}{ll}
\hline Criterion & Median score (range) \\
\hline $\begin{array}{l}\text { Blood culture positive and flush } \\
\text { associated rigor }\end{array}$ & $10(7-10)$ \\
$\begin{array}{l}\text { Blood culture positive and flush } \\
\text { associated fever }\end{array}$ & $10(5-10)$ \\
$\begin{array}{l}\text { Infection does not resolve until line is } \\
\text { removed }\end{array}$ & $10(2-10)$ \\
$\begin{array}{l}\text { Blood culture negative and flush } \\
\text { associated rigor }\end{array}$ & $9(3-10)$ \\
$\begin{array}{l}\text { Repeated blood culture of candida } \\
\text { Repeated blood culture of coagulase } \\
\text { negative staphylococcus in an } \\
\text { afebrile patient }\end{array}$ & $9(3-10)$ \\
$\begin{array}{l}\text { Sequential infection with the same } \\
\text { organism }\end{array}$ & $8(6-10)$ \\
$\begin{array}{l}\text { Quantitative difference in bacteria from } \\
\text { line and peripheral blood samples }\end{array}$ & $8(3-10)$ \\
$\begin{array}{l}\text { Blood culture negative and flush } \\
\text { associated fever }\end{array}$ & $7(1-10)$ \\
$\begin{array}{l}\text { Single blood culture of coagulase } \\
\text { negative staphylococcus in a febrile } \\
\text { patient }\end{array}$ & $6(3-9)$ \\
\hline
\end{tabular}

to $10 \mathrm{ml}$ ), and ports with $5 \mathrm{ml}$ of either $10 \mathrm{U} / \mathrm{ml}$ heparinised saline (range 5 to $10 \mathrm{ml}$ ) or 100 $\mathrm{U} / \mathrm{ml}$ heparinised saline (range 2.5 to $10 \mathrm{ml}$ ) in $62 \%$. Nurses were taught line care in $80 \%$ of centres, compared with $33 \%$ for doctors. Parents were taught in $95 \%$, with $67 \%$ providing written information as well.

Opinions were sought from surgeons, oncologists, and microbiologists about criteria for diagnosing infection due to CVC colonisation. Forty replies were received from 11 centres, ranging from strong agreement (score 10) to strong disagreement (score 0 ) regarding whether a particular clinical or microbiological finding was indicative of CVC colonisation. Table 2 shows that the range of answers for the first two questions was small, but for the remainder it was large, indicating wide variation in the criteria for diagnosing CVC colonisation.

\section{Discussion}

This study showed that $26 \%$ of CVCs were reinsertions. This compares with previous reports of $23 \%$ reinsertions ${ }^{1}$ and of irreversible line failure rates of $20-53 \% .^{12}$ Nonrandomised prospective studies have shown that removal of catheters for any complication is significantly more likely with external catheters than with subcutaneous ports, ${ }^{23}$ although one randomised study showed no difference. ${ }^{4}$ The reasons for reinsertion were not identified in our study, but a prospective study of UK centres is clearly needed to ascertain which variations in CVC practice are associated with complications leading to untimely removal.

Surgical insertion technique is likely to be important for subsequent mechanical problems. The right internal jugular vein, used in $53 \%$ cases in our study, is chosen as the entry vein because of its accessibility and as a reliable route to the right atrium. The line tip was positioned in the right atrium in $62 \%$ of our patients, which may facilitate sampling and minimise the risk of thrombus formation. ${ }^{5}$ Other operative techniques, for example a cuff suture, are recommended to prevent early line dislodgement, ${ }^{6}$ although it is unclear yet whether an exit site suture is also beneficial. The value of perioperative antibiotic use is still unproven. The relevance of performing other procedures under the same anaesthetic with respect to future line complications has not previously been reported.

Flushing solution and frequency may be important for line infection and occlusion. Published studies range from minimal flushing without heparin ${ }^{7}$ to twice daily with $10 \mathrm{ml}$ of 10 $\mathrm{U} / \mathrm{ml}$ heparinised saline. ${ }^{3}$ If these methods could be shown to be equally effective, minimal flushing procedures could have considerable cost saving implications. The importance of teaching line flushing to medical staff to reduce line infection is highlighted in one study. ${ }^{8}$

The difficulty in diagnosing CVC infection arises in establishing whether the line is colonised with the infecting organism and is therefore the primary focus of infection. Our results show wide variations in how CVC colonisation is diagnosed. The pragmatic solution is a prospective study relating the overall pattern of clinical presentation and laboratory findings to outcome, without attempting a formal diagnosis of CVC colonisation. It should then be possible to estimate relative predictive values of clinical and microbiological features.

Centres participating in the study: Aberdeen, Belfast, Birmingham, Cambridge, Cardiff, Christie Hospital (Manchester), Dublin, Edinburgh, Glasgow, Great Ormond Street Hospital (London), Leeds, Leicester, Manchester Children's Hospital, The Middlesex Hospital (London), Newcastle, Nottingham, Oxford, Sheffield, Southampton, and St Bartholomew's Hospital (London).

We are grateful to the UKCCSG/PONF centres for recruiting patients and to Michael Cole for statistical support.

Merck Sharpe and Dohme Ltd provided financial support and D A Tweddle was supported by the Leukaemia Research Fund.

The UKCCSG is supported by the Cancer Research Campaign.

1 Sellden H, Lannering B, Marky I, Nilsson K. Long-term use of central venous catheters in paediatric oncology treatment. Acta Anaesthesiol Scand 1991;35:315-9.

2 Ingram J, Weitzman S, Greenberg ML, Parkin P, Filler R. Complications of indwelling venous access lines in the pediatric hematology patient. Am $\mathcal{f}$ Pediatr Hematol Oncol 1991;13:130-6

3 Mirro J, Rao BN, Stokes DC, et al. A prospective study of Hickman/Broviac catheters and implantable ports in
paediatric oncology patients. $\mathcal{F}$ Clin Oncol 1989;7:214-22.

4 Mueller B, Skelton J, Calendar DPE, et al. A prospective randomised trial comparing the infectious and noninfectious complications of an externalised catheter versus a subcutaneously implanted device in cancer patients. $\mathcal{F}$ a subcutaneously implanted

Clin Oncol 1992;10:1943-8.
5 Lucas H, Attard-Montalto SP, Saha V, Bristow A, Kingston JE, Eden OB. Central venous catheter tip position and malfunction in a pediatric oncology unit. Pediatr Surg Int 1996;11:159-63.

6 Wiener ES, McGuire P, Stolar CJH, et al. The CCSG prospective study of venous access devices: an analysis of insertions and causes for removal. F Pediatr Surg 1992;27: 155-64.

7 Smith S, Dawson S, Hennessey R, Andrew M. Maintenance of the patency of indwelling central venous catheters: is heparin necessary? Am 7 Pediatr Hematol Oncol 1991;13: 141-3.

8 Puntis JWL, Holden CE, Smallman S, Finkel Y, George RH, Booth IW. Staff training: a key factor in reducing intravascuBooth IW. Staff training: a key factor in reducing inther sepsis. Arch Dis Child 1990;65:335-7.
lar catheter 